\title{
A critical literature review on emotional intelligence in addiction
}

\author{
Revisão crítica da literatura em inteligência emocional e adição
}

Keila Pereira Leite, Fernanda de Marzio Pestana Martins, Alisson Paulino Trevizol, (D) Julio Ricardo de Souza Noto, Elisa Brietzke (iD

\begin{abstract}
Introduction: Emotional intelligence (EI) has been defined as the ability to perceive, understand, use and manage emotions. Studying EI could potentially be useful in understanding addictive behaviors as well as for designing and planning interventions.

Objectives: To conduct a critical review on EI impairment in addiction disorders.

Methods: MEDLINE/PubMed, Google Scholar, Cochrane, LILACS, and SciELO databases were searched. Articles that used the standardized Mayer-Salovey-Caruso Emotional Intelligence Test (MSCEIT) instrument to assess EI in people with addictions and healthy controls were selected for the review.

Results: We selected seven articles assessing EI and its associations with addiction disorders, mainly alcohol abuse and cocaine dependence. Most studies reported that individuals with addiction disorders had worse EI scores when compared to controls.

Conclusion: Overall, the studies reviewed demonstrated that addictions are associated with EI deficits, compared to controls. However, aspects such as the small number of addictive disorders analyzed, methodological issues related to instruments for assessment of IE and the lack of follow-up remain significant limitations.
\end{abstract}

Keywords: Emotional intelligence, substance-related disorders, addiction disorder, impulsive buying disorder.

\section{Resumo}

Introdução: Inteligência emocional (IE) é definida como a habilidade de perceber, compreender, utilizar e manejar emoções. Estudos em IE são potencialmente úteis na compreensão de comportamentos relacionados a adições, assim como no planejamento de intervenções.

Objetivos: Realizar revisão crítica da literatura em comprometimento da IE em adições.

Métodos: A busca foi realizada nas plataformas MEDLINE/ PubMed, Google Scholar, Cochrane, LILACS e SciELO. Artigos que utilizaram o Mayer-Salovey-Caruso Emotional Intelligence Test (MSCEIT) para a avaliação de IE em adições e controles saudáveis foram incluídos na revisão.

Resultados: Nós selecionamos sete artigos que avaliaram IE e sua associação com dependência química e não química, especialmente abuso de álcool e dependência de cocaína. A maior parte dos estudos reportou que indivíduos com transtornos relacionados ao uso de substâncias apresentaram valores inferiores na MSCEIT em comparação a controles saudáveis.

Conclusão: De forma geral, os estudos revisados demostraram uma associação entre dependência química e déficits em IE na comparação com controles saudáveis. No entanto, a reduzida quantidade de transtornos de uso de substância analisada, problemas metodológicos relacionados a instrumentos de avaliação de IE e a ausência de seguimento dos sujeitos incluídos nos estudos são limitações significativas.

Descritores: Inteligência emocional, transtornos relacionados ao uso de substâncias, dependência química, dependência não química. 


\section{Introduction}

Emotional intelligence (EI) is a theoretical construct first proposed by John Mayer and Peter Salovey in the 1980s to define the ability to deal with emotions. ${ }^{1}$ They affirm that individuals with high EI have certain tools for dealing with emotions, such as perceiving and expressing emotions; using them in thought and understanding and reasoning with emotional information; and managing emotions. ${ }^{1-3}$ According to these authors, EI has four dimensions: perception; understanding; management; and use of emotions. . $^{4}$

Individuals with high EI scores usually manage their lives effectively, adjusting goals and objectives to social reality and inner reality, and have better health outcomes. ${ }^{6}$ In this sense, it could be hypothesized that subjects with higher EI are likely to develop and retain certain good characteristics like self-acceptance; positive relationships with others; autonomy; maintenance of life purpose; and personal growth, all of which are putatively protective against mental illnesses. ${ }^{7}$ Furthermore, if EI could be improved by psychosocial interventions, it could also be a potential target for interventions. ${ }^{8,9}$

Since higher EI scores are related to better impulse control and better stress management after adverse events, ${ }^{10}$ we hypothesized that they would have an impact on Addiction Disorders. Although the EI construct has acquired notable popularity, it remains virtually unexplored within Psychiatry. The objective of this study was to critically review the literature regarding EI in addiction disorders, discussing the implications of this construct with regard to EI assessment and prevention and treatment of addiction disorders.

\section{Methods}

Articles were identified for review by conducting a literature search on several databases, performed on October 10, 2017. The following search strategy was used for PubMed and similar strategies were used for other databases: ((( ("Emotional Intelligences" OR "Intelligence, Emotional" OR "Intelligences, Emotional" OR "Social Intelligence" OR "Intelligence, Social" OR "Intelligences, Social" OR "Social Intelligences"))) AND ((MSCEIT OR "Mayer-Salovey-Caruso Emotional Intelligence Test"))) AND (("Amphetamine Related Disorders" OR "Disorder, Amphetamine-Related" OR "Disorders, Amphetamine-Related" OR "Amphetamine Abuse" OR "Abuse, Amphetamine" OR "Amphetamine Addiction" OR "Addiction, Amphetamine" OR "Amphetamine Dependence" OR "Dependence, Amphetamine" OR "Cocaine Related Disorders" OR
"Cocaine-Related Disorder" OR "Disorder, CocaineRelated" OR "Disorders, Cocaine-Related" OR "Cocaine Abuse" OR "Abuse, Cocaine" OR "Cocaine Dependence" OR "Dependence, Cocaine" OR "Dependences, Cocaine" OR "Cocaine Addiction" OR "Addiction, Cocaine" OR "Drug Dependence" OR "Dependence, Drug" OR "Drug Addiction" OR "Addiction, Drug" OR "Drug Habituation" OR "Habituation, Drug" OR "Substance Use Disorders" OR "Disorder, Substance Use" OR "Substance Use Disorder" OR "Substance Abuse" OR "Abuse, Substance" OR "Abuses, Substance" OR "Substance Abuses" OR "Substance Dependence" OR "Dependence, Substance" OR "Substance Addiction" OR "Addiction, Substance" OR "Drug Abuse" OR "Abuse, Drug" OR "Drug Use Disorders" OR "Disorder, Drug Use" OR "Drug Use Disorder" OR "Dependence, Heroin" OR "Heroin Addiction" OR "Addiction, Heroin" OR "Heroin Abuse" OR "Abuse, Heroin" OR "Dependence, Morphine" OR "Morphine Addiction" OR "Addiction, Morphine" OR "Morphine Abuse" OR "Abuse, Morphine" OR "Disorder, Opioid-Related" OR "Opiate Dependence" OR "Dependence, Opiate" OR "Opiate Addiction" OR "Addiction, Opiate" OR "Narcotic Abuse" OR "Abuse, Narcotic" OR "Abuses, Narcotic" OR "Narcotic Abuses" OR "Narcotic Dependence" OR "Dependence, Narcotic" OR "Narcotic Addiction" OR "Addiction, Narcotic" OR "Alcohol Dependence" OR "Dependence, Alcohol" OR "Alcoholic Intoxication, Chronic" OR "Chronic Alcoholic Intoxication" OR "Intoxication, Chronic Alcoholic" OR "Alcohol Addiction" OR "Addiction, Alcohol" OR "Alcohol Abuse" OR "Abuse, Alcohol" OR "Disorder, Tobacco Use" OR "Tobacco Use Disorders" OR "Tobacco-Use Disorder" OR "Disorder, Tobacco-Use" OR "Nicotine Use Disorder" OR "Disorder, Nicotine Use" OR "Nicotine Use Disorders" OR "Use Disorder, Nicotine" OR "Tobacco Dependence" OR "Dependence, Tobacco" OR "Tobacco Dependences" OR "Nicotine Dependence" OR "Dependence, Nicotine")).

The reference lists of the papers selected were manually searched for additional pertinent references. The abstracts of all articles found were read by two authors (KPL, FDMPM) to select those that would be included in our analysis. After we had selected articles on the basis of their abstracts, the full texts were read by all three authors, to ensure the best evaluation possible (see Figure 1).

We searched for relevant original articles in English, Portuguese or Spanish that used the Mayer-SaloveyCaruso Emotional Intelligence Test (MSCEIT) to assess $\mathrm{EI}$ in adults and compared scores between subjects with an addictive disorder and healthy controls or between subjects with different addictive disorders. References were excluded from our review if another instrument was used to assess EI or if not all of the MSCEIT 
questions were used. Review articles and those with repeated data were also excluded.

One significant issue is that different explanatory concepts of EI have been translated into different instruments to assess EI as a construct. The MSCEIT was developed to assess EI as proposed by the Mayer and Salovey model, which has four dimensions. ${ }^{11}$ The psychometric properties of the MSCEIT were studied by Rossen et al. ${ }^{11}$ and reviewed by Maul. ${ }^{12}$ For the purpose of this review, we excluded articles that did not use MSCEIT to evaluate EI in their samples. We did this for two main reasons: MSCEIT is currently the only EI ability test that covers all four dimensions of $\mathrm{EI}^{9}$ and it is the only instruments which has had its psychometric properties properly studied, with good results for validity. ${ }^{11,12}$

\section{Results}

Our searches returned 34 articles assessing associations between addictions and the MSCEIT score.
After reading abstracts and full texts, we selected seven articles for qualitative analysis. These articles were organized into two groups: Substance Abuse Disorders (6 articles) and Impulsive Buying (1 article).

We also found two previous reviews on the subject, but one of them was not read by the authors because of the language it was written in (Hungarian). ${ }^{13}$ The second article was a systematic review ${ }^{14}$ and did not report original data. This review was performed in 2009 and included articles using different instruments to assess EI, without giving any priority to validated questionnaires. The main results of our review are shown in Table 1.

\section{Substance use disorders (SUD)}

Hertel et al. used the MSCEIT to evaluate subjects with SUD ( $n=35)$, Major Depressive Disorder (MDD) ( $n=31$ ) and Borderline Personality Disorder (BPD) ( $n=$ 19), compared to 94 healthy subjects. ${ }^{6}$ Approximately $90 \%$ of the SUD sample comprised subjects with alcohol use disorder. The SUD group had a lower total EI score than the healthy subjects and the other clinical

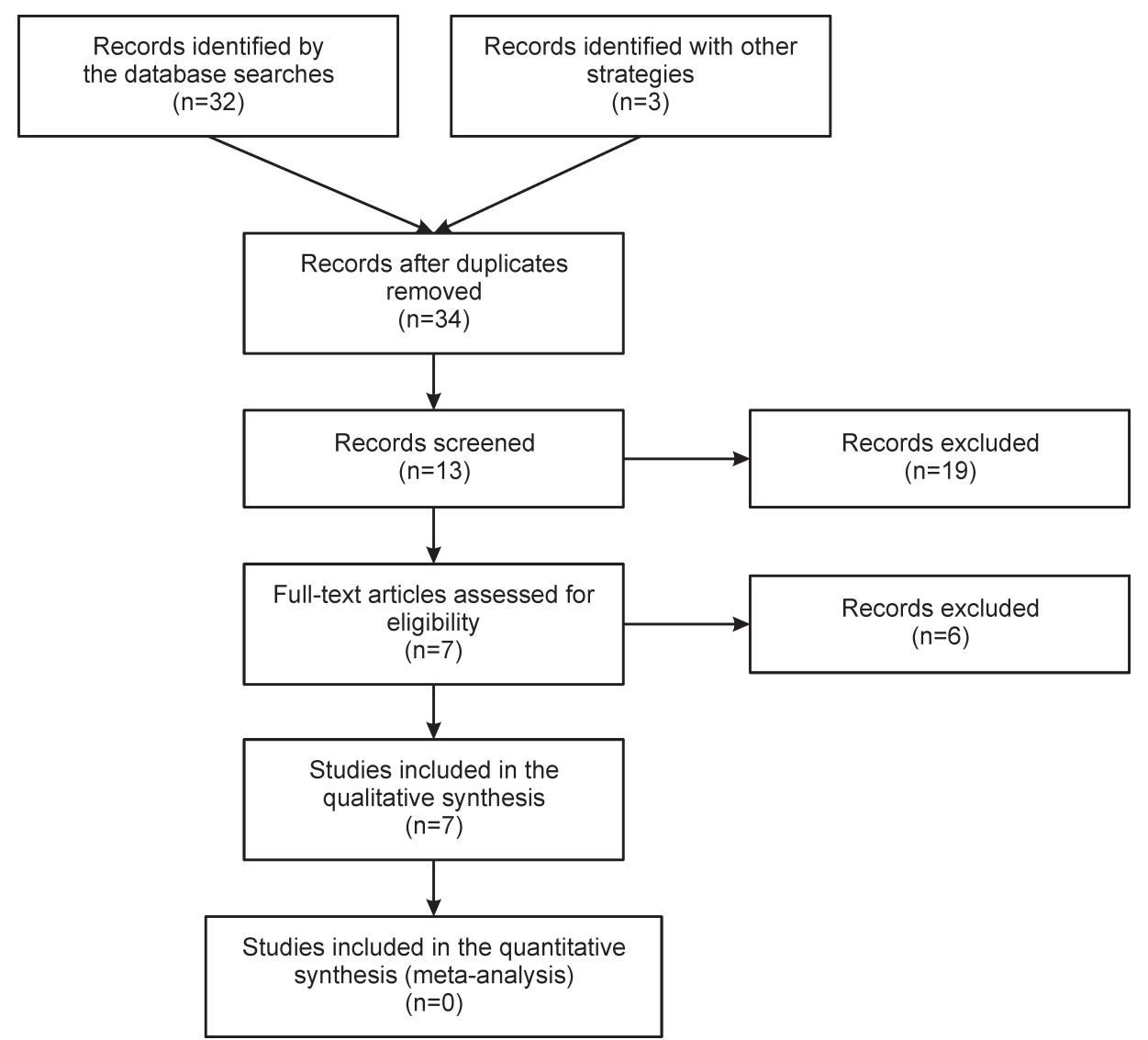

Figure 1 - The Preferred Reporting Items for Systematic Reviews and Meta-Analyses (PRISMA) flow chart 
groups. Patients with SUD, and also the BPD subset, had worse EI performance in the MSCEIT understanding and regulating domains than the nonclinical subset. However, the group with SUD performed as well as the control group for perception of emotions. The study authors point out that the MSCEIT perception evaluation may lead to some bias.
Tomczak administered the Bar-On Emotional Quotient-Inventory (EQ-i) and the MSCEIT to 193 students from the University of Alabama in order to assess these students' Trait EI (which includes selfperceptions, competencies, abilities and personality traits); and Ability EI (which represents a combination of emotional-reasoning skills and abilities). ${ }^{15}$ Both trait

Table 1 - Research investigating the relationship between EI and addiction disorders

\begin{tabular}{|c|c|c|c|c|c|}
\hline Disorder & Study & $\begin{array}{l}\text { Study } \\
\text { design }\end{array}$ & Sample size & Results & Study limitations and Bias \\
\hline $\begin{array}{l}\text { Addictions- } \\
\text { substance } \\
\text { use disorder }\end{array}$ & Hertel $^{6}$ & $\begin{array}{l}\text { Cross- } \\
\text { sectional }\end{array}$ & $\begin{array}{l}31 \text { patients with } \\
\text { unipolar depression, } \\
19 \text { with borderline } \\
\text { personality disorder, } \\
35 \text { with substance } \\
\text { abuse disorder ( } 90 \% \text { : } \\
\text { alcohol) and } 94 \text { healthy } \\
\text { controls }\end{array}$ & $\begin{array}{l}\text { The group with clinical substance } \\
\text { use disorders performed worse } \\
\text { than the control group for the } \\
\text { overall MSCEIT score and the } \\
\text { understanding emotions ability. }\end{array}$ & $\begin{array}{l}\text { - No identification of } \\
\text { comorbidities, psychiatric } \\
\text { diagnoses or use of } \\
\text { psychotropic medication } \\
\text { - Small sample size } \\
\text { - Unable to establish causal } \\
\text { effects }\end{array}$ \\
\hline
\end{tabular}

\begin{tabular}{|c|c|c|c|}
\hline $\begin{array}{l}\text { Addictions- } \\
\text { substance } \\
\text { use disorder }\end{array}$ & Tomczak $^{15}$ & $\begin{array}{l}\text { Cross- } \\
\text { sectional }\end{array}$ & $\begin{array}{l}193 \text { university students } \\
\text { ( } 74 \% \text { alcohol; } 39 \% \\
\text { marijuana) }\end{array}$ \\
\hline
\end{tabular}

$\begin{array}{lll}\text { Addictions- } & \text { Fox }^{9} & \begin{array}{l}\text { Cross- } \\ \text { substance }\end{array} \\ \text { sectional } \\ \text { use disorder }\end{array}$

use disorder marijuana)

72 abstinent, treatment-seeking cocaine patients and 52 healthy controls
High levels of substance abuse were related to lower MSCEIT total scores and lower scores for management of emotions were a significant predictor of substance abuse.

Patients' understanding and managing emotions abilities 2 were significantly deficient when compared to the control group.

- Study 1: In healthy controls, women obtained better scores for facilitation and management of emotions compared to the men. However, this difference was not observed in the CDA group. - Study 2: Progesterone had a positive impact on facilitation of thoughts in both men and women, when compared to placebo.

$\begin{array}{llll}\begin{array}{l}\text { Addictions- } \\ \text { substance }\end{array} & \begin{array}{l}\text { Romero- } \\ \text { Ayuso }^{17}\end{array} & \begin{array}{l}\text { Cross- } \\ \text { sectional }\end{array} & \begin{array}{l}25 \text { maintaining cocaine } \\ \text { abstinence and } 25 \\ \text { healthy controls }\end{array} \\ \begin{array}{l}\text { use disorder } \\ \text { healthy }\end{array} & & & \end{array}$

$\begin{array}{llll}\begin{array}{l}\text { Addictions } \\ \text { - substance }\end{array} & \text { Lizeretti }^{18} & \begin{array}{l}\text { Cross- } \\ \text { sectional }\end{array} & \begin{array}{l}24 \text { patients with } \\ \text { agoraphobia, } 18 \text { with } \\ \text { abuse }\end{array} \\ \text { disorder } & & \begin{array}{l}\text { cocaine addiction and } \\ 20 \text { with dysthymia or } \\ \end{array} \\ & & \text { minor depression. }\end{array}$

\begin{tabular}{|c|c|c|}
\hline $\begin{array}{l}\text { Addictions- } \\
\text { impulse }\end{array}$ & Peter $^{19}$ & $\begin{array}{l}\text { Cross- } \\
\text { sectional }\end{array}$ \\
\hline
\end{tabular}

Cocaine addicted patients had a significantly lower total MSCEIT score than the control group, with understanding and managing emotions the most deficient skills.

Patients with cocaine dependence had better total EI score when compared to the agoraphobia sample. However, they use of emotions.

152 university students The MSCEIT total score was negatively associated with impulsive buying behavior and understanding and managing of emotions as skills with significant impairment.
- Absence of a mixture of internal and external factors - Sample with unequal proportions of males and females

- Included subjects with comorbid alcohol and nicotine dependence - Elevated number of individuals with lifetime anxiety disorder

- In the first study, there were more cigarette smokers in the CDA group when compared to the control group

- The CDA group in study 1 had, in general, more years of alcohol use

-Cocaine-dependent patients were receiving cognitive behavioral therapy -Restricted number of balloons in the experimental analog task

-Small sample size -Absence of healthy control group

-Samples not matched by sex

-Unable to establish causal effects

-Small sample size

CDA = cocaine-dependent individuals who also abuse alcohol; EI = emotional intelligence; MSCEIT = Mayer-Salovey-Caruso Emotional Intelligence Test. 
and ability emotional intelligence were significantly associated with substance abuse (especially alcohol) and reactive/immature delinquency (as assessed by the Measure of Delinquency-Revised [MOD-R]). The MOD-R is a 22-item, self-report instrument designed to measure the rate, frequency, and quality of antisocial acts in a college sample. ${ }^{15}$ In the results, the author reported that both EI measures (trait and emotional ability) scored lower in the substance abuse sample. Regarding the four domains of EI in the ability model, the MSCEIT management of emotions score was a significant predictor of substance abuse. This result provides support for the hierarchical structure of the ability model, with the managing emotions domain at the top of the hierarchy.

Milivojevic et al. carried out two analyses: in the first one, they administered the MSCEIT to 98 early abstinent cocaine-dependent individuals with alcohol abuse (CDA) (55 male/43 female) and 56 healthy individuals (28 male/28 female). ${ }^{16}$ They also investigated the menstrual cycle phases of the women in the sample. For the second analysis, they administered the MSCEIT to 18 CDA subjects (19 male/ 9 female) who were given progesterone (400 mg/day) or placebo for seven days. In the first analysis, healthy women scored higher for facilitation of thoughts and management of emotions than healthy men. However, the difference between genders was not observed in the CDA group, suggesting that women in this group have impaired emotional abilities, supposedly explained by differences in hormones levels. Among all of the women in the study, those who were in the menstrual cycle phase with high levels of progesterone had better scores for management of emotions than those who were in the low progesterone levels phase. In the second analysis, these authors observed that exogenous progesterone improved facilitation of thoughts in both sexes when compared to the placebo group. Thus, their hypothesis that impairment of EI in women in the CDA group was probably related to a change in progesterone levels was supported.

Using the MSCEIT test, Lizeretti et al. investigated EI in a sample with cocaine dependence $(C D)(n=18)$, dysthymia/minor depression $(n=20)$ and agoraphobia. ${ }^{18}$ When compared to the other two groups, CD patients did better in the total score and EI domains, except for the use of emotions, in which the CD sample performed worse than patients with agoraphobia. The CD sample had the worst MSCEIT score for regulation of emotions, but performed better in perception of emotions.

Using the MSCEIT with a sample of 72 patients with cocaine dependence (35 men/37 women) and 52 healthy individuals ( 26 men/26 women), Fox et al. ${ }^{9}$ found significant EI deficits in the cocaine-dependent group when compared to the control group, especially for understanding and managing emotions. These were associated with increased perception of stress and with difficulties in impulse control. The authors also found that low IQ had a negative impact on MSCEIT total score in the CD sample. However, this was not observed in the control group.

Romero-Ayuso et al. used the MSCEIT and the Balloon Analogue Risk Task (BART) with 25 individuals with no history of drug use and 25 in treatment at the Addictive Behaviors Unit, abstinent by time of evaluation. ${ }^{17}$ Cocaine-addicted participants had a significantly lower EI score than the control group and strategic EI (understanding and managing emotions) were the most deficient. These data are consistent with the fact that these patients exhibit difficulties with analyzing more complex emotions and with establishing pleasant interpersonal relationships. Additionally, difficulty with regulating their emotional responses also makes it more difficult for them to manage stressful situations (lack of decisiveness in uncontrollable situations).

\section{Impulsive buying}

We found one article assessing EI correlations with impulsive buying. Peter et al. examined EI's impact on impulsive buying and self-esteem ${ }^{19}$ in a sample of 152 students. EI was assessed using the MSCEIT and the CEIS (Consumer Emotional Intelligence Scale). The CEIS is an 18-item scale developed by Kidwell et al., based on the MSCEIT. ${ }^{20}$ It is domain-specific (marketing), whereas the MSCEIT is domain-generic. They found EI scores to be negatively correlated with impulsive buying and positively correlated with selfesteem. Analysis of the four domains of EI demonstrated that the strategic branches of EI (understanding and managing emotions) were inversely correlated with impulsive buying. The same was not observed with the experiential domains. The strategic domains were positively correlated with self-esteem.

\section{Discussion}

Overall, the results of the studies analyzed in this review support the hypothesis that addictions are related to EI deficits, especially when individuals with SUD are compared to healthy controls. However, the small sample size and the small number of studies preclude conclusions about how the different EI domains evaluated by the MSCEIT might operate to influence behavior. For example, we could take into account Tomczak's findings reporting that poor management 
of emotions was a predictor of substance abuse ${ }^{15}$ and hypothesize that this could be one of the reasons involved in the initial stages of addictive behaviors. Along the same lines, we could think that in relation to Impulsive Buying, the worse scores observed in the strategic domains of EI (understanding and managing emotions) could predispose these individuals to poor impulse control. Indeed, these findings reinforce the theory that poor management of emotions may be related to poor impulse control and increased risk of addiction, but, since impulsivity is a heterogeneous and multicausal construct, studies are needed to test this hypothesis. Regarding comparisons with other mental disorders, the different studies did not agree about the magnitude or type of EI deficits in patients with SUD and other mental disorders. This may be due to the small number of studies and to the differences in sample selection.

One unanswered question which naturally emerges is whether it would be possible to prevent or treat Addiction Disorders by improving EI. Since high EI is negatively related to SUD, we reason that the answer would be positive and this hypothesis would be plausible, although it remains largely underexplored. To date, very few studies have included interventions specifically designed to improve EI in mental disorders. Most of them had samples composed of students and their results cannot be applied to clinical populations. ${ }^{21}$ These interventions usually apply methodologies that include role-playing, short lectures, discussions in groups, twoperson words, lectures and personal diaries to monitor emotional experiences. ${ }^{21}$

\section{Limitations and future research directions}

The samples in the studies included in this review were very different in relation to age, gender, duration of disease, intellectual level, substance of choice and other qualities. It was not possible to perform a metaanalysis because of the differences between the samples and the different methods employed in the studies.

Most of the items that made up this critical review are analytical case-control studies, which detected differences in EI scores between subjects with addictions and some other mental disorders and healthy controls. This review is not therefore able to establish that the low EI score is causally associated with addiction disorders. Furthermore, the fact that not all of the studies regarded intellectual ability as a variable to be investigated is also a limitation. One of the articles demonstrated that IQ had a negative impact on total MSCEIT score for the cocainedependent subset only. When the same analysis was performed for the healthy controls, no correlation was found. This suggests that intellectual ability has an impact on EI, but the data on this subject are insufficient to lead to definitive conclusions.

Another limitation of the present study is the selection of only the MSCEIT as instrument for the evaluation of EI, since this restriction caused the exclusion of a large number of articles that used other instruments, such as the Bar-On EQI, the Trait Meta-Mood Scale (TMMS)24 and the Emotional Intelligence Scale (EIS). ${ }^{22-24}$

Thus, further longitudinal studies should be performed to elucidate whether there is a cause-andeffect relationship between EI and addictive disorders. New interventions for prevention of mental disorders and enhancement of quality of life could be designed following these studies. Furthermore, future studies should assess EI using more than one instrument, enabling broader interpretations of EI. Differentiation between negative and positive emotions and evaluation of EI within a certain time period should also be included in further studies.

\section{Acknowledgements}

Keila Pereira Leite receives a scholarship from Conselho Nacional de Desenvolvimento Científico e Tecnológico (CNPq). Elisa Brietzke is supported by Coordenação de Aperfeiçoamento de Pessoal de Nível Superior (CAPES), CNPq, Fundação de Amparo à Pesquisa do Estado de São Paulo (FAPESP), and by a L'Oreal/UNESCO/Brazilian Academy of Science for Women in Science Award.

\section{Disclosure}

No conflicts of interest declared concerning the publication of this article.

\section{References}

1. Mayer JD, Salovey P, Caruso DR, Cherkasskiy L. Emotional intelligence. In: Sternberg RJ, Kaufman SB, editors. The Cambridge handbook of intelligence. New York: Cambridge University Press; 2011. p. 528-49.

2. Salovey $P$, Mayer JD. Emotional Intelligence. Imagin Cogn Pers 1990;9:185-211.

3. Mayer JD, Salovey P. The intelligence of emotional intelligence. Intelligence. 1993;17:433-42.

4. Mayer JD, Salovey P. What is emotional intelligence? In: Salovey $P$, Sluyter DJ, editors. Emotional development and emotional intelligence: Educational implications. New York: BasicBooks; 1997. p. 3-34.

5. Mikolajczak M, Nelis D, Hansenne M, Quoidbach J. If you can regulate sadness, you can probably regulate shame: Associations between trait emotional intelligence, emotion regulation and coping efficiency across discrete emotions. Pers Individ Dif. 2008;44:1356-68. 
6. Hertel J, Schutz A, Lammers $\mathrm{CH}$. Emotional intelligence and mental disorder. J Clin Psychol. 2009;65:942-54.

7. Bagshaw M. Emotional intelligence - Training people to be affective so they can be effective. Ind Commer Train. 2000;32:61-5.

8. Zhou J, George JM. Awakening employee creativity: The role of leader emotional intelligence. Leadersh Q. 2003;14:545-68.

9. Fox HC, Bergquist KL, Casey J, Hong KA, Sinha R. Selective cocaine-related difficulties in emotional intelligence: relationship to stress and impulse control. Am J Addict. 2011;20:151-60.

10. Mayer JD, Salovey P, Caruso DR, Sitarenios G. Measuring emotional intelligence with the MSCEIT V2.0. Emotion. 2003;3:97-105.

11. Rossen $\mathrm{E}$, Kranzler JH, Algina J. Confirmatory factor analysis of the Mayer-Salovey-Caruso Emotional Intelligence Test V 2.0 (MSCEIT). Pers Individ Dif. 2008;44:1258-69.

12. Maul A. The validity of the Mayer-Salovey-Caruso Emotional Intelligence Test (MSCEIT) as a measure of emotional intelligence. Emot Rev. 2012;4:394-402.

13. Kun B, Demetrovics Z. [The role of emotional intelligence in addiction disorders]. Psychiatr Hung. 2010;25:503-24.

14. Kun B, Demetrovics Z. Emotional intelligence and addictions: a systematic review. Subst Use Misuse. 2010;45:1131-60.

15. Tomczak V. The impact of emotional intelligence on substance abuse and delinquency in a college sample: the comparison of emotional intelligence traits versus abilities [dissertation]. Tuscaloosa: University of Alabama; 2010.

16. Milivojevic V, Sinha R, Morgan PT, Sofuoglu M, Fox HC. Effects of endogenous and exogenous progesterone on emotional intelligence in cocaine-dependent men and women who also abuse alcohol. Hum Psychopharmacol. 2014;29:589-98.

17. Romero-Ayuso D, Mayoral-Gontan Y, Trivino-Juarez J-M. Emotional intelligence, risk perception in abstinent cocaine dependent individuals. Actas Esp Psiquiatr. 2016;44:72-8.
18. Lizeretti NP, Oberst UE, Chamarro A, Farriols N. Evaluación de la inteligencia emocional en pacientes con psicopatologia: resultados preliminares usando TMMS-24 y el MSCEIT. Ansiedad Estrés. 2006;12:355-64.

19. Peter $\mathrm{P}, \mathrm{Krishnakumar} \mathrm{S}$. Emotional intelligence, impulse buying and self-esteem: the predictive validity of two ability measures of emotional intelligence. Adv Consum Res 2010;37:877-8.

20. Kidwell B, Childers TL, Hardesty D. Consumer emotional intelligence: conceptualization, measurement, and the prediction of consumer decision making. J Consum Res. 2008;35:154-66.

21. Mayer JD, Caruso D, Salovey P. Emotional intelligence meets traditional standards for an intelligence. Intelligence. 1999;27:267-98.

22. Bar-On R. The Bar-On model of emotional-social intelligence (ESI). Psicothema. 2006;18 Suppl:13-25.

23. Delhom I, Gutierrez M, Lucas-Molina B, Melendez JC. Emotional intelligence in older adults: psychometric properties of the TMMS-24 and relationship with psychological well-being and life satisfaction. Int Psychogeriatr. 2017;29:1327-34.

24. Lane AM, Meyer BB, Devonport TJ, Davies KA, Thelwell R, Gill GS, et al. Validity of the emotional intelligence scale for use in sport. J Sports Sci Med. 2009;8:289-95.

\section{Correspondence:}

Elisa Brietzke

Rua Borges Lagoa, 570

Vila Clementino

04038-000 - São Paulo - Brazil

Tel. : + 55 (11) 55764991

E-mail: elisabrietzke@hotmail.com 